\title{
An Empirical Research on the Relationship between the Number of Varieties in Distribution Terminals of the Manufacturer and Consumer Buying Behavior
}

\author{
Wenchao Liu, Jiexia Li \\ Department of Business Administration, Jilin University of Finance and Economics, Changchun, China \\ liuwenchao211@yahoo.com.cn; jack_lee1cn@yahoo.com.cn
}

\begin{abstract}
The majority of consumers purchase decision is made in the retail terminal, so manufacturers pay more and more attention to the point of sale influence consumer buying behaviours. This paper selects specific types of retailers as the experimental environment, selects the specific products as the research object, uses the "S-O-R" theory, and manipulates the number of varieties in the retail terminal of specific manufacturer, to find out whether the product varieties changes, the product purchase volume of specific manufacturer will change. The study found a lot of important conclusions. Firstly, as products which sold in retail terminal from a manufacturer vary from less to more, products sale will appear first increased then decreased. When the product variety reached a critical value, product sales reached a vertex. Secondly, when the products number which sold by a manufacturer less than or equal to the critical value, increase of the products number will positive influence consumers purchase behaviour for the manufacturer's product, and improve the total sales. Thirdly, when the products number which sold by a manufacturer greater than or equal to the critical value, increase of the products number will negative influence consumers purchase behaviour for the manufacturer's product, and reduce the total sales.

Index Terms -Product varieties; purchase behaviour in store; Quasi-Experimentation Design based Field Research
\end{abstract}

\section{I . Introduction}

Up to $70 \%-80 \%$ of consumers purchase decision is made in the retail stores. Manufacturers are increasingly aware of the importance of influencing consumers' purchase decision at the point of sale ${ }^{[1]}$. Because of the existence of game relationship between producers and retailers ${ }^{[2]}$, and the same retail store sales of similar products supply from multiple manufacturers, therefore, specific manufacturer is more concerned about how to control the retail mall internal stimuli in order to influence consumer purchase behavior of its products.

We found in a study in 2011 that there is a certain relationship between specific manufacturer's goods varieties sales in a retail store and its sales amount. But we didn't know the relationship is just the simple linear relations, or with a certain curve. Moreover, specific manufacturer's products saled in retail stores are compete with other producers. whether the manufacturer can control its product varieties, to influence consumer in-store purchase behavior, and make consumers to purchase its products more is unknow. There is no special research about it. So we do the research on these problems can provide marketing strategy guidance for manufacturers competition in the same retailer environment.

\section{II . Literature Review and Research Hypotheses}

With the development of tens of thousands of new products each year, manufacturers have more and more brightly refurbished different products under the same brand [3]. This also led to consumers increasingly difficult to choose the right products on store shelves ${ }^{[4][5]}$. Consumers buy soda were took 25 seconds in the supermarket, but now the average time is 40 seconds to complete the purchase decision ${ }^{[6]}$.

Maybe consumers may think, more merchandise options so that they are more likely to find the right products. But we can see an example, brand A has 6 jam flavours, while brand B has 24 jam flavours, we may think consumers would more interest in brand B. But when they really want to choose and buy, they would spend 10 times more in brand $\mathrm{B}$ than brand A [7].

In the actual purchase decision, compared to more choice, as long as the same product quality, in fact, consumer preference for less ${ }^{[8] 9]}$. Some consumers do have a clear preference for a particular product, they may benefit from the choice of a specific product. But too many product selection may make most other consumers feel troublesome and difficult to choose ${ }^{[10][11][12]}$. The disadvantage of product categories increasing may lead to consumers have to face too many product varieties and to buy rival products ${ }^{[13]}$. Marketers also found that too many varieties of goods will make consumers get dizzy, and too much product function also will give consumers the frustration. Therefore, Philips launched "let science and technology innovation become more simple" in $2004^{[14][15]}$.

Consumer attitudes towards commodity is not equivalent to the purchase behaviour. The sales amount is more suitable to actual measure of consumer buying behavior after the goods variety changes. In previous studies, few literature about the relationship between goods variety and sales amount. Even if there are individual studies reveal the relationship between the two, but they were choose foreign goods as research object and foreign retailers as the research environment. Deborah Ball (2006) select the Nescafe Kit Kat as the research object and the United States retailers as the research environment. There were few literature on Chinese consumers' purchasing behavior in domestic retailers ${ }^{[16]}$.

Previous literature mostly agree "too many types of merchandise will make consumers get dizzy" ${ }^{[14][15]}$, also agree 
that "consumers prefer less product variety" $\left.{ }^{[8][9}\right]$, but did not quantify the variety of goods to what extent will reduce consumers purchase behavior.

Previous studies mostly occurs in a specific retailer ${ }^{[6]}$, and did not define the conclusions of the study in a particular retail environment is applicable to other similar types of retailers ${ }^{[7]}$, therefore, the research conclusion may lack of extension ${ }^{[17]}$.

Based on the theory review and analysis above, this paper puts forward the following hypotheses:

H1: As products which sold in retail terminal from a manufacturer vary from less to more, products sale will appear first increased then decreased. When the product variety reached a critical value, product sales reached a vertex.

H2: When the products number which sold by a manufacturer less than or equal to the critical value, increase of the products number will positive influence consumers purchase behaviour for the manufacturer's product, and improve the total sales.

H3: When the products number which sold by a manufacturer greater than or equal to the critical value, increase of the products number will negative influence consumers purchase behaviour for the manufacturer's product, and reduce the total sales.

\section{Design of Experimental Research}

The research was on the basis of S-O-R theory ${ }^{1}$, and ues the Quasi-Experimentation Design ${ }^{[18]}$. We selected some representative manufacturer's product and the real retail stores as experimental environment. And then we manipulate different independent variables and observe the experimental subjects for a long time, to observe the changes in the dependent variables and their causal relationship. After careful argumentation, the research team select $\mathrm{T}$ brand corn juice as experimental products because of consumer purchase this product were sensitivity influenced by environmental ${ }^{[19][20]}$. We also selected the same type of retail shopping malls ${ }^{2}$ as experimental environment. These shopping malls were located in Shenyang and Dalian City. In Shenyang and Dalian city, a total of 67 retailers had $\mathrm{T}$ brand corn juice beverage sales and meet the above experimental environment requirements, of which 42 of retailers agreed to cooperate with the study (see Table 1).

The experiment was from October 1 to December 31, 2012. According to the experimental requirements, these stores should keep their $\mathrm{T}$ corn juice beverage varieties and quantity unchanged during the experiment. We take the beverage variety as experimental independent variable. Moreover, the retail stores should not carry out any

\footnotetext{
1 "S-O-R" is short of "stimulus-organism-response

${ }^{2}$ The retailer should meet 3 conditions the same time: The store sales of home appliances (including TV, refrigerator) and fresh food; sales area is not less than 6000 square meters; cashier number not less than 20.
}

promotional activities besides the $\mathrm{T}$ brand corn juice beverage manufacturers' unified promotion.

\section{IV . Experimental Results and Analysis}

A . Results and Analysis of Experiment One

We saw the experiment retailers on the whole. According to their average number of $\mathrm{T}$ brand corn juice products sold within three months respectively from small to large, we analysed the sales amount change respectively. After the experiment, we got the sales amount for each retail store in POS machine. We can see the experimental results in table 1.

Table 1 Participated Retailers and Their Monthly Sales Amount

\begin{tabular}{|c|c|c|c|c|c|c|c|}
\hline No & retailer & $\begin{array}{c}\text { T brand } \\
\text { corn juice } \\
\text { products } \\
\text { number }\end{array}$ & $\begin{array}{c}\text { Sales per } \\
\text { month/000 }\end{array}$ & No & retailer & $\begin{array}{c}\text { T brand corn } \\
\text { juice products } \\
\text { number }\end{array}$ & $\begin{array}{c}\text { Sales per } \\
\text { month/000 }\end{array}$ \\
\hline 1 & R001 & 7 & 4 & 22 & R022 & 13 & 13 \\
\hline 2 & R002 & 7 & 9 & 23 & R023 & 14 & 23 \\
\hline 3 & R003 & 8 & 13 & 24 & R024 & 14 & 27 \\
\hline 4 & R004 & 8 & 10 & 25 & R025 & 15 & 15 \\
\hline 5 & R005 & 8 & 8 & 26 & R026 & 15 & 13 \\
\hline 6 & R006 & 9 & 3 & 27 & R027 & 16 & 22 \\
\hline 7 & R007 & 9 & 13 & 28 & R028 & 16 & 19 \\
\hline 8 & R008 & 10 & 12 & 29 & R029 & 17 & 21 \\
\hline 9 & R009 & 11 & 5 & 30 & R030 & 17 & 8 \\
\hline 10 & R010 & 11 & 21 & 31 & R031 & 19 & 12 \\
\hline 11 & R011 & 12 & 9 & 32 & R032 & 20 & 15 \\
\hline 12 & R012 & 21 & 12 & 33 & R033 & 27 & 19 \\
\hline 13 & R013 & 21 & 10 & 34 & R034 & 27 & 16 \\
\hline 14 & R014 & 22 & 13 & 35 & R035 & 27 & 3 \\
\hline 15 & R015 & 22 & 6 & 36 & R036 & 28 & 15 \\
\hline 16 & R016 & 22 & 8 & 37 & R037 & 28 & 19 \\
\hline 17 & R017 & 23 & 16 & 38 & R038 & 29 & 20 \\
\hline 18 & R018 & 24 & 13 & 39 & R039 & 29 & 22 \\
\hline 19 & R019 & 24 & 18 & 40 & R040 & 32 & 11 \\
\hline 20 & R020 & 25 & 17 & 41 & R041 & 34 & 7 \\
\hline 21 & R021 & 26 & 16 & 42 & R042 & 37 & 8 \\
\hline
\end{tabular}

If we descript the data of $\mathrm{T}$ brand corn beverage varieties and sales amount which showed in table 1 into plotted curves and mark out the trend line, we can get such as analysis results shown in figure 1.

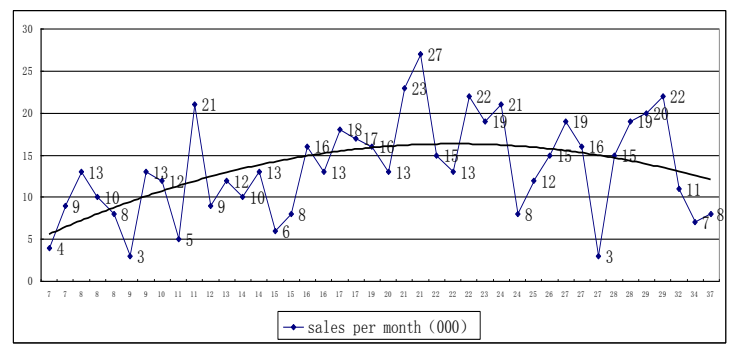

Figure 1 Sales Change of Participated Retailers in Experiment 
From table 1 and figure 1, we can see that, overall, with the increase of $\mathrm{T}$ brand corn juice beverage product varieties selling in retail shops, the average monthly sales amount have shown increase first and then decrease. When the product varieties reached 21 , which is the critical value, the sales amount reached the maximum value of $¥ 27000$. The results support the hypothesis 1 .

\section{B . Results and Analysis of Experiment Two}

We divided experiment retailers into two groups: The first group of retailers were selling $\mathrm{T}$ brand corn juice varieties less than or equal to the critical point (21). And we got a total of 24 retailers. The second group of retailers were selling $\mathrm{T}$ brand corn juice varieties greater than or equal to the critical point (21). And we got a total of 19 retailers. The No.24 retailer was the store which has critical point and extreme sales amount. After the experiment, we got the amount of sales for $\mathrm{T}$ corn juice beverage products from each experimental retail store POS machine.

\section{1) Results of the First Group}

We took "T brand corn juice varieties" as independent variable X1, "T brand corn juice sales amount" as dependent variable Y1. Through regression analysis by SPSS, we got the results as table 2 .

Table 2 Results of Regression Analysis for the First Group

\begin{tabular}{|c|c|c|c|c|c|c|}
\hline \multicolumn{7}{|c|}{ Model summary } \\
\hline model & $\mathrm{R}$ & $\mathrm{R}^{2}$ & \multicolumn{2}{|c|}{ Adjust $\mathrm{R}^{2}$} & \multicolumn{2}{|c|}{ Standard error } \\
\hline 1 & $.644^{\mathrm{a}}$ & .415 & \multicolumn{2}{|c|}{.388} & \multicolumn{2}{|c|}{4.63591} \\
\hline \multicolumn{7}{|c|}{ a. Predictor variables: (constant), $\mathrm{T}$ brand corn juice varieties } \\
\hline \multicolumn{7}{|c|}{ Anova $^{b}$} \\
\hline \multicolumn{2}{|c|}{ model } & SS & $\mathrm{df}$ & \multirow{2}{*}{$\frac{\text { MSS }}{335.142}$} & $\mathrm{~F}$ & Sig. \\
\hline \multirow{3}{*}{1} & ESS & 335.142 & 1 & & 15.594 & $.001^{\mathrm{a}}$ \\
\hline & RSS & 472.816 & 22 & 21.492 & & \\
\hline & TSS & 807.958 & 23 & & & \\
\hline
\end{tabular}

a. Predictor variables: (constant), T brand corn juice varieties

b. Dependent variable: T brand corn juice sales amount per month('000)

\begin{tabular}{|c|c|c|c|c|c|c|}
\hline \multicolumn{7}{|c|}{ Coefficient $^{\mathrm{a}}$} \\
\hline & \multirow[t]{2}{*}{ model } & \multicolumn{2}{|c|}{$\begin{array}{l}\text { Not standard } \\
\text { coefficient }\end{array}$} & \multirow[t]{2}{*}{$\begin{array}{c}\text { standard } \\
\text { coefficient }\end{array}$} & \multirow[t]{2}{*}{$\mathrm{t}$} & \multirow[t]{2}{*}{ Sig. } \\
\hline & & B & S.E. & & & \\
\hline & ( constant) & 1.252 & 2.992 & & .418 & .680 \\
\hline 1 & $\begin{array}{c}\mathrm{T} \text { brand } \\
\text { corn juice } \\
\text { varieties }\end{array}$ & .846 & .214 & .644 & 3.949 & .001 \\
\hline
\end{tabular}

a. Dependent variable: T brand corn juice sales amount per month('000)

The results of regression analysis showed that, the $\mathrm{F}$ value is 15.594 , significant at 0.01 level. The regression equation is significant and can be used to explain the relationship between variable $\mathrm{X} 1$ and variable $\mathrm{Y} 1$. The $\mathrm{R}^{2}$ value is 0.415 , indicates that the variable $\mathrm{X} 1$ can be explained by the variable Y1 for variation of $41.5 \%$. It means "T brand corn juice beverage products variety" can explain $41.5 \%$ of "consumers purchase behavior of T brand" statisticly. Look at the regression coefficient, non-standardized coefficient is 0.846 , which means there is a positively correlation between "T brand corn juice beverage product variety" and "consumers purchase behavior for all $\mathrm{T}$ brand products". It also indicates when the $\mathrm{T}$ brand corn juice beverage products is less than the critical value, increase the product variety will lead to consumers buy more T brand products. So it supported H2.

\section{2) Results of the Second Group}

We took "T brand corn juice varieties" as independent variable X2, "T brand corn juice sales amount" as dependent variable Y2. Through regression analysis by SPSS, we got the results as table 3 .

Table 3 Results of Regression Analysis for the Second Group

\begin{tabular}{|c|c|c|c|c|c|c|c|}
\hline \multicolumn{8}{|c|}{ Model summary } \\
\hline \multicolumn{3}{|c|}{ model } & $\mathrm{R}$ & $\mathrm{R}^{2}$ & Adjust $\mathrm{R}^{2}$ & \multicolumn{2}{|c|}{ Standard error } \\
\hline \multicolumn{3}{|c|}{1} & $.461^{\mathrm{a}}$ & .213 & .166 & \multicolumn{2}{|c|}{5.63060} \\
\hline \multicolumn{8}{|c|}{ a. Predictor variables: (constant), $\mathrm{T}$ brand corn juice varieties } \\
\hline \multicolumn{8}{|c|}{ Anova $^{b}$} \\
\hline \multicolumn{3}{|c|}{ model } & SS & df & MSS & $\mathrm{F}$ & Sig. \\
\hline \multirow{3}{*}{\multicolumn{2}{|c|}{1}} & ESS & 145.458 & 1 & 145.458 & 4.588 & $.047^{\mathrm{a}}$ \\
\hline & & RSS & 538.963 & 17 & 31.704 & & \\
\hline & & TSS & \multicolumn{2}{|c|}{684.421} & & & \\
\hline \multicolumn{8}{|c|}{ a. Predictor variables: (constant), $\mathrm{T}$ brand corn juice varieties } \\
\hline \multicolumn{8}{|c|}{ b. Dependent variable: $\mathrm{T}$ brand corn juice sales amount per month(' 000$)$} \\
\hline \multicolumn{8}{|c|}{ Coefficient $^{\text {aa }}$} \\
\hline \multirow{2}{*}{\multicolumn{3}{|c|}{ model }} & \multicolumn{2}{|c|}{$\begin{array}{c}\text { Not standard } \\
\text { coefficient }\end{array}$} & $\begin{array}{c}\text { standard } \\
\text { coefficient }\end{array}$ & $\mathrm{t}$ & Sig \\
\hline & & & B & S.E. & & & \\
\hline \multirow[b]{2}{*}{1} & & $\operatorname{stan} t)$ & 33.028 & 8.345 & & 3.958 & .001 \\
\hline & & $\begin{array}{l}\text { rand } \\
\text { juice } \\
\text { eties }\end{array}$ & -.662 & .309 & -.461 & -2.142 & .047 \\
\hline
\end{tabular}

The results of regression analysis showed that, the $\mathrm{F}$ value is 4.588, significant at 0.05 level. The regression equation is significant and can be used to explain the relationship between variable $\mathrm{X} 2$ and variable $\mathrm{Y} 2$. The $\mathrm{R}^{2}$ value is 0.213 , indicates that the variable $\mathrm{X} 2$ can be explained by the variable Y2 for variation of $21.3 \%$. It means "T brand corn juice beverage products variety" can explain $21.3 \%$ of "consumers purchase behavior of $\mathrm{T}$ brand" statisticly. Look at the regression coefficient, B coefficient is -0.662 , which means there is a negatively correlation between " $\mathrm{T}$ brand corn juice beverage product variety" and "consumers purchase behavior for all $\mathrm{T}$ brand products". It also indicates when the $\mathrm{T}$ brand corn juice beverage products is greater than the critical value, increase the product variety will lead to consumers buy less $\mathrm{T}$ brand products. So it supported H3. 


\section{Conclusions and Suggestions}

\section{A. Conclusions}

In this study, we selected specific convenience product as experimental objects and 42 stores wich meet the requirement as experimental environment. Through the manipulation of product varieties and promotional activities, and after three month research, we got some important conclusions:

Firstly, As convenience products which sold in retail terminal from a manufacturer vary from less to more, products sale will appear first increased then decreased. When the product variety reached a critical value, product sales reached a vertex.

Secondly, When the convenience products number which sold by a manufacturer less than or equal to the critical value, increase of the products number will positive influence consumers purchase behaviour for the manufacturer's product, and improve the total sales.

Thirdly, When the convenience products number which sold by a manufacturer greater than or equal to the critical value, increase of the products number will negative influence consumers purchase behaviour for the manufacturer's product, and reduce the total sales.

\section{B. Marketing Suggestions}

Based on the conclusion of this study, we put forward some suggestions for the convenience goods manufactures which choose large supermarkets as their marketing channels.

Firstly, the number of product varieties sold in some retail store need to follow certain rules: as the number of the manufacturer's product varieties increase from less to more, the total sales amount will first increase and then decrease. Therefore, it is very important to find out the specific product varieties critical value.

Secondly, as a convenience products manufacturer, before reaching the critical value, increasing the number of good varieties will be beneficial to increase the total sales amount.

Thirdly, as a convenience products manufacturer, after reaching the critical value, increasing the number of good varieties will be negative affect the total sales amount.

\section{References:}

[1] Jie-xia Li, Dong-chang LIU, "Marketing: from consumers to shoppers," Business Management Magazine, no.2, pp.89-91, Feb 2008

[2] Chernev, Alexander, "Jack of All Trades or Master of One? Product Differentiation and Compensatory Reasoning in Consumer Choice," Journal of Consumer Research, vol.34,no.3, pp.430- 444, March 2007.
[3] Kuksov, Dmitri, and J. Miguel Villas-Boas, "When More Alternatives Lead to Less Choice," Marketing Science, vol.29, no.3, pp.507-524, March 2010.

[4] Diehl, Kristin, Cait Poynor, "Great Expectations?! Assortment Size, Expectations and Satisfaction," Journal of Marketing Research, vol.47, no.4, pp.312-322, April 2010.

[5] Chernev, Alexander, "The Role of Purchase Quantity in Assortment Choice: The Quantity- Matching Heuristic," Journal of Marketing Research, vol.45, no.4, pp.171-181, April 2008.

[6] Cassie Mogilner, Tamar Rudnick, Sheena Iyengar, "The Mere Categorization Effect: How the Presence of Categories Increases Choosers' Perceptions of Assortment Variety and Outcome Satisfaction," Journal of Consumer Research, vol.35, no.2, pp. 202-215, Feb 2008.

[7] Redden, Joseph P., Stephen J. Hoch, "The Presence of Variety Reduces Perceived. Quantity," Journal of Consumer Research, vol.36, no.10, pp. 406-417, Oct 2009.

[8] Chernev, Alexander and Ryan Hamilton, "Assortment Size and Option Attractiveness in Consumer Choice among Retailers ," Journal of Marketing Research, vol.46, no.6, pp. 410-420, June 2009.

[9] Richard A. Briesch, Pradeep K. Chintagunta, Edward J. Fox, "How Does Assortment Affect Grocery Store Choice?" Journal of Marketing Research, vol.46, no.2, pp.176-189, Feb 2009.

[10] Sela, Aner, Jonah Berger, Wendy Liu, "Variety, Vice, and Virtue:How Assortment Size Influences Option Choice," Journal of Consumer Research, vol.35, no.4, pp.941-951, April 2009.

[11] Gourville, John T., Dilip Soman, "Overchoice and Assortment Type: When and Why Variety Backfires," Marketing Science, vol.24, no.3, pp.382-395,March 2005.

[12] Chernev, Alexander, "When More Is Less and Less Is More: The Role of Ideal Point Availability and Assortment in Choice," Journal of Consumer Research, vol.30, no.9, pp. 170-183, Sep 2003.

[13] Broniarczyk, Susan M.., "Product Assortment. In Curtis P. Haugtved, Paul M. Herr, Frank R. Kardes (Eds.)Handbook of Consumer Psychology," NY: Psychology Press, 755-799.

[14] Barry Schwartz, "The Paradox of Choice: Why More Is Less," New York: Harper Collins Ecco, 2004.

[15] Sheena S. Iyengar, Mark R. Lepper, "When choice is demotivating: Can one desire too much of a good thing?" Journal of Personality and Social Psychology, vol.79, no.6, pp. 995-1006,June 2000.

[16] Jie-xia LI, Wen-chao LIU, "Relationship between in-store Share-ofShelf Space and in-store Shopping Behavior-from Manufacturer's Perspective," Journal of economic management, no.5,pp.105-113,May 2012.

[17] Curhan, Ronald C, "The Relationship between Shelf Space and Unit Sales in Supermarkets," Journal of Marketing Research, vol.9, no.4, pp.406- 412, April 1972.

[18] Qing MIAO, "A new approach to management methodology: a field study based on the experimental design," Journal of Zhejiang University, vol.37, no.6, pp.73-80, June 2007.

[19] Brown, W., Tucker, W, "The marketing center: vanishing shelf space," Atlanta Economic Review, no.4, pp.9-13, April 1961.

[20] Curhan, Ronald C, "Shelf Space Allocation and Profit Maximization in Mass Retailing," Journal of Marketing, vol.37, no.3, pp.54- 60, March 1973. 